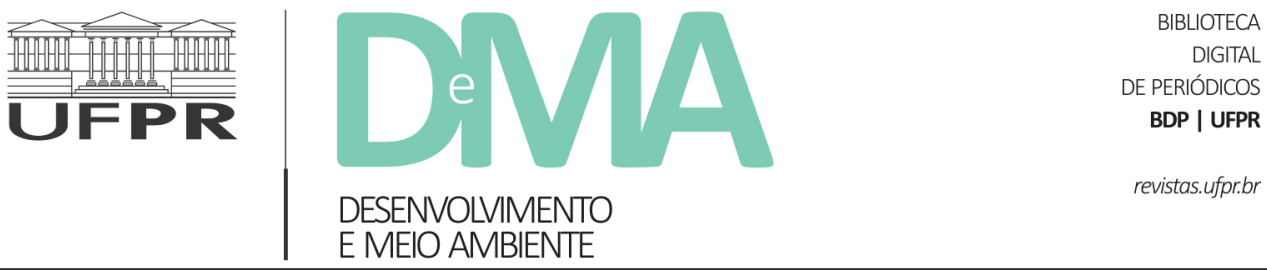

\title{
Eficiência sistêmica em empreendimentos econômicos solidários de reciclagem: construção e aplicação de indicadores multidimensionais
}

\section{Systemic efficiency in solidarity economic enterprises of recycling: construction and application of multidimensional indicators}

\author{
Joice Pinho MACIEL ${ }^{1}$, Adriane Vieira FERRARINI ${ }^{1 *}$ \\ ${ }^{1}$ Universidade do Vale do Rio dos Sinos (UNISINOS), São Leopoldo, RS, Brasil. \\ *E-mail de contato: adrianevf@unisinos.br
}

Artigo recebido em 11 de setembro de 2019, versão final aceita em 4 de maio de 2020, publicado em 26 de agosto de 2020.

\begin{abstract}
RESUMO: A mensuração da eficiência de organizações econômicas se funda usualmente na racionalidade canônica da economia de mercado, para a qual a maximização de lucros é o propósito central, e o faturamento econômico, seu indicador de êxito. Empreendimentos do campo da economia solidária, cuja eficiência econômica é indissociável de outras dimensões, carecem de instrumentos para a captação desta multidimensionalidade. Este trabalho visa a analisar a aplicação de indicadores multidimensionais para a mensuração da eficiência de empreendimentos econômicos solidários (EES) de reciclagem através da apresentação do estudo de caso na Cooperativa UNIVALE, localizada no Estado do Rio Grande do Sul (Brasil). Para tanto, foi desenvolvido o Índice de Eficiência Multidimensional de Cooperativas de Reciclagem (IEMCR) através de pesquisa exploratória, de revisão teórica e análise de instrumentos (Ferrarini, 2008; Kraychete, 2012; Gaiger \& Grupo Ecosol, 2014). O IEMCR foi elaborado a partir de uma visão sistêmica da realidade e mediante a aglutinação de indicadores simples referidos às dimensões econômica, social, política, ambiental e humana. Os resultados da aplicação do IEMRC evidenciaram que os EES pesquisados são eficientes do ponto de vista multidimensional, pois compatibilizam a eficiência econômica com o bem-estar e cidadania dos seus membros; constituem importantes espaços de luta política; geram impacto social e ambiental positivo e contribuem para formas de desenvolvimento mais sustentável e inclusivo. A diversidade de indicadores também oportunizou a identificação de fragilidades e a elaboração de uma pauta propositiva para a melhoria da eficiência multidimensional dos EES, podendo ser um instrumento aplicável tanto a processos de pesquisa quanto de diagnóstico em atividades de assessoria a organizações econômicas que privilegiam o impacto social e ambiental.
\end{abstract}

Palavras-chave: eficiência; economia solidária; indicadores multidimensionais; sustentabilidade.

Desenvolv. e Meio Ambiente usa uma Licença Creative Commons - Atribuição-NãoComercial-SemDerivações 4.0 Internacional 
ABSTRACT: Measuring the efficiency of economic organizations is usually based on the canonical rationality of the market economy, for which profit maximization is the central purpose, and economic invoicing its indicator of success. Enterprises in the field of solidarity economy, whose economic efficiency is inseparable from other dimensions, lack instruments to capture this multidimensionality. This work aims to analyze the application of multidimensional indicators for measure the efficiency of solidarity economic enterprises (SEE) on recycling through the presentation of the case study at UNIVALE Cooperative, located in the State of Rio Grande do Sul (Brazil). To this end, the Multidimensional Recycling Cooperatives Efficiency Index (IEMCR) was developed through exploratory research, theoretical review and instrument analysis (Ferrarini, 2008; Kraychete, 2012; Gaiger \& Ecosol Group, 2014). The IEMCR was elaborated based on a systemic view of reality and through the agglutination of simple indicators related to the economic, social, political, environmental and human dimensions. The results of the application of the IEMRC showed that the SEEs surveyed are efficient from a multidimensional point of view, since they make economic efficiency with the welfare and citizenship of their members; they constitute important spaces for political struggle; they generate positive social and environmental impact and contribute to more sustainable and inclusive forms of development. The diversity of indicators has also made it possible to identify weaknesses and draw up a guideline for improving the multidimensional efficiency of SEE, and which can be an instrument applicable to both research and diagnostic processes in advisory activities for economic organizations that focus on social and environmental impact.

Keywords: efficiency; solidarity economy; multidimensional indicators; sustainability.

\section{Introdução}

Detrás do dinheiro, há um mundo de paixões, há a psicologia humana (Edgar Morin).

É crescente o campo de economias alternativas, cuja atividade econômica volta-se fundamentalmente a um propósito social, intrinsecamente conectado à geração de impactos benéficos ao meio ambiente. A economia solidária se constitui como um campo econômico alternativo de referência no Brasil, reacendendo os valores fundamentais do cooperativismo, integrando a riqueza de experiências autóctones e articulando um conjunto de iniciativas populares.

Enquanto o faturamento econômico é o indicador de mensuração da eficiência de uma empresa formal - mantido ou incrementado pela exigência de crescente otimização da relação custo/benefício - os empreendimentos do campo da economia solidária possuem outras motivações para a condução do trabalho coletivo. Se o objetivo é melhorar a vida das pessoas, gerar benefícios sociais e impactar positivamente o meio ambiente, não se pode avaliar apenas os resultados econômicos ou financeiros.

Este trabalho visa a analisar a aplicação de indicadores multidimensionais - elaborados a partir de uma visão sistêmica da realidade - para a mensuração da eficiência de empreendimentos econômicos solidários (EES) de reciclagem. A eficiência foi definida e mensurada a partir de cinco dimensões: econômica, social, política, ambiental e humana. A aplicação dos indicadores multidimensionais foi realizada e validada na cooperativa UNIVALE, cujas características se aproximam dos EES típicos de reciclagem devido a duas razões. Em primeiro lugar, pelas dificuldades enfrentadas, tais como: estrutura física e maquinários insatisfa- 
tórios e exposição a riscos relacionados à saúde e segurança ocupacional. Em segundo lugar, porque os trabalhadores da UNIVALE migraram de uma condição de catadores individuais e vivenciaram o ciclo de constituição de uma forma associativa de trabalho.

O texto inicialmente apresentará uma desconstrução do conceito de eficiência, canonicamente entendido numa perspectiva economicista mercantil. Posteriormente, serão apresentados os indicadores multidimensionais de eficiência sistêmica, cuja elaboração se valeu de instrumentos e pesquisas desenvolvidas no campo da economia solidária e do desenvolvimento local. Ao final, será demonstrada a aplicação dos indicadores, oportunizando uma análise quali-quantitativa da eficiência em EES no campo da reciclagem.

\section{Economia solidária e eficiência}

A economia solidária congrega iniciativas de vários cidadãos, produtores e consumidores, que passaram a se organizar para o desenvolvimento de inúmeras atividades econômicas, segundo princípios de cooperação, autonomia e gestão democrática (Gaiger \& Laville, 2009). Tais atividades ocorrem mediante a socialização dos recursos produtivos e da utilização de critérios igualitários que, em sua maioria, atendem a um coletivo de trabalhadores desempregados (Razeto, 1990; Veronese et al., 2017). Suas expressões concretas permanecem bastante variadas, compreendendo pequenas unidades produtivas, associações de beneficiamento ou apoio à produção familiar, grupos de produção ecológica, comunidades produtivas autóctones, cooperativas de trabalho, de comercialização e de consumidores ou usuários de serviços de saúde, educação, etc., iniciativas de comércio justo, finanças solidárias, clubes de troca, etc. (Gaiger \& Grupo Ecosol, 2014).

Embora tenha ganhado notoriedade a partir de sua expansão recente na década de 1990, a economia solidária dá continuidade e novo alento a uma história extensa, na qual se contam inúmeras experiências de solidarismo popular. Ao Sul, tanto no Brasil como na América Latina em geral, a economia solidária possui antecedentes longínquos, a começar pelas formas autóctones pré-colombianas e pelos sistemas coletivos adotados pelos afrodescendentes libertos (quilombolas) (Veronese et al., 2017).

Ao Norte, a economia solidária evoca a longa história associativa dos trabalhadores, iniciada no século XIX. Desde então, essa vertente tem cumprido um papel de alargamento da experiência humana, ao manter vigentes outros princípios de produção de bens, de organização do trabalho e de circulação da riqueza, distintos da racionalidade estrita do capital (Gaiger \& Laville, 2009, p. 163).

A economia solidária é movida por uma racionalidade econômica distinta da mercantil, pela qual a economia é um processo de institucionalização da interação entre o ser humano e o ambiente natural e social para o atendimento de necessidades humanas. Tal racionalidade é denominada pelo economista Karl Polanyi de substantiva, cujos princípios convergem com a economia pré-clássica de Aristóteles.

Polanyi argumenta que sistemas históricos se especificam pelo modo como instituem formas de intercâmbio na produção substantiva da vida material para além da mercantil. Contudo, na contemporaneidade, a identificação automática da economia com sua forma de mercado se deve à uni- 
versalização de uma racionalidade formal em que a economia é uma relação entre finalidades e recursos escassos, cuja finalidade volta-se à acumulação do excedente a partir do abstrato e racional jogo matemático de preços (Polanyi, 1977; Granovetter, 1985; Machado, 2012).

Nesta perspectiva formal, presente na economia clássica e neoclássica, a economia é como sistema autorregulado e desimbricado (desimbedded), e o ser humano é visto como indivíduo atomizado, agindo de forma racional a partir de seus próprios interesses, com independência dos grupos e classes sociais. Apesar de ser uma ciência ideológica, histórica e geograficamente condicionada e da negação de aspectos sociológicos, o conceito de economia como sinônimo de mercado se universalizou e monopolizou a semântica do termo economia até os dias de hoje (Polanyi, 1977).

A mensuração de eficiência é fundamental a qualquer atividade econômica. Dentre as definições, eficiência pode ser sintetizada como a "quantidade de recursos usados para atingir um objetivo organizacional" (Daft, 1999, p. 5). Sob a égide da economia formal, a eficiência capitalista refere-se essencialmente à exigência de otimização da relação custo/benefício, pela decisiva incidência desta sobre a rentabilidade ou a taxa de lucro dos negócios (Gaiger, 2009).

Classicamente, o custo representa perdas de capital inevitáveis no processo produtivo, relativas a consumo de matérias-primas, depreciação de máquinas, tratamento de efluentes, remuneração da força de trabalho, impostos, etc. (Miller, 1981), o que implica a necessidade de reduzi-lo, sob o prisma dos investidores. Dada a separação entre estes e a massa dos trabalhadores, as decisões sobre eficiência são uma prerrogativa do capital, nos limites dos seus fins intrínsecos e como parte da sua lógica de reprodução ampliada [...] A eficiência capitalista não considera, senão utilitariamente, benefícios sociais gerados pela ação econômica, tais como postos de trabalho, valorização do ser humano, preservação do ambiente natural e qualidade de vida (Gaiger, 2009, p. 169).

Este cálculo, em que as contas têm que fechar independentemente das condições de produção ou das consequências geradas, está na origem do paradoxo da sociedade contemporânea, em que o crescimento exponencial da riqueza é simultâneo ao aumento sem precedente das desigualdades (Ferrarini, 2008) e à recente elevação dos índices de fome e pobreza no mundo (FSIN, 2018). No caso dos EES, que reanimam a combinação aristotélica entre economia, política e natureza, como pensar a noção de eficiência? E como mensurá-la?

A análise da eficiência em EES não pode abster-se de considerar a natureza dos fins buscados, os quais se vinculam à satisfação de necessidades e a objetivos materiais, socioculturais e ético-morais dos indivíduos e da coletividade, imediatos ou de longo prazo (Gaiger, 2009). Na economia solidária, a eficiência

compreende a capacidade de os processos e meios utilizados promoverem [...] a materialização de benefícios sociais - e não meramente monetários ou econômicos -, a geração de efeitos benéficos ao entorno em que se situem as iniciativas em questão, a garantia de longevidade para estas e a concretização de externalidades positivas sobre o ambiente natural, em favor de sua sustentabilidade (Gaiger, 2009, p. 169).

O trabalho é fator organizador dos EES, seu principal recurso produtivo, físico e intelectual e sua razão de ser (Razeto, 1990; Coraggio, 2009). 
Por conseguinte, a eficiência passa a ser entendida sob uma visão sistêmica e integrada às dimensões não econômicas (Gaiger, 2009). O olhar sistêmico possibilita avaliar todas as partes de forma articulada, sem privilegiar uma dimensão específica. $\mathrm{O}$ princípio de não somatividade do sistema, ou seja, o todo é maior do que a soma das partes, é fundamental para a compreensão, não apenas da indissociabilidade entre as partes, como das propriedades superiores que emergem a partir da interação entre as múltiplas dimensões (Morin, 2008).

Tal indissociabilidade é ainda mais evidente nas atividades de reciclagem. A exaustão da vida útil dos aterros sanitários, a poluição, a presença de catadores nos lixões, a escassez de áreas disponíveis para a criação de outros aterros e o desperdício de materiais ainda complexos, indicam a necessidade de uma revisão do modo atual com o material restante após a utilização dos bens ou dos serviços (Ribeiro et al., 2014).

No início dos anos de 1980, com os debates sobre o desenvolvimento sustentável, as questões do tratamento adequado dos resíduos e a reciclagem passam a fazer parte dos principais temas ambientais discutidos, evidenciando sua importância em caráter global e local. Os resíduos sólidos se tornaram um imenso desafio nas cidades brasileiras, sendo definidos como aqueles que se apresentam em estados sólido e semissólido e que resultam de atividades da comunidade, de origem industrial, doméstica, hospitalar, comercial, agrícola, de serviços e de varrição (Brasil, 2010).

A gestão integrada de resíduos sólidos envolve a elaboração, implantação e execução de um modelo de administração dos mesmos, considerando a participação ativa das autoridades competentes e de setores da sociedade, com destaque para a atu- ação dos catadores e para a responsabilização dos geradores ao longo da cadeia produtiva de bens.

$\mathrm{O}$ processo de reciclagem envolve várias etapas, que incluem desde o processo de gerenciamento de resíduos descartados, passando pela coleta, a triagem, o enfardamento, a comercialização do material, a logística de transporte, o beneficiamento pela indústria até o desenvolvimento do mercado para um novo produto (Silva et al., 2011). Os materiais coletados são triados de acordo com suas características físicas, a exemplo do papel, papelão, plásticos, metais, alumínio e vidros. Cada material possui um valor determinado, que se dá devido ao tratamento que ele receberá em seu processo de transformação ou reciclagem (Ribeiro, et al.,2014).

A reciclagem tem sido reconhecida como um setor produtivo de ganhos econômicos, o que vem sendo demonstrado em estudos recentes, segundo os quais 116.610 toneladas foram recicladas no ano de $2018,4,4 \%$ a mais que em 2017 . Ou seja, houve recuperação de $22 \%$ das embalagens pós-consumo colocadas no mercado por empresas participantes do programa Dê a Mão para o Futuro - Reciclagem, Trabalho e Renda, associadas à Associação Brasileira da Indústria de Higiene Pessoal Perfumaria e Cosméticos (ABIHPEC), à Associação Brasileira das Indústrias de Produtos de Higiene, Limpeza e Saneantes (ABIPLA) e à Associação Brasileira das Indústrias de Biscoitos, Massas Alimentícias e Pães \& Bolos Industrializados (ABIMAPI), movimentando cerca de R\$ 62 milhões. Em 2017, as cooperativas e associações acompanhadas pela Associação Nacional dos Catadores e Catadoras de Materiais Recicláveis (ANCAT), em torno de 166, registraram faturamento de $\mathrm{R} \$ 39$ milhões com a comercialização das 84 mil toneladas coletadas. Em 2018, com uma média de 133 cooperativas e 
associações participantes, foram comercializados R\$ 32 milhões, equivalente a cerca de 67 mil toneladas coletadas (ANCAT 2017/2018; ABRELPE, 2018/2019).

A valorização econômica ocorreu devido ao aumento de consumo nos grandes centros urbanos e, consequentemente, do descarte e do valor das matérias-primas utilizadas para a produção de bens de consumo demandados pela sociedade. A reciclagem possibilita a transformação de resíduos em matéria-prima novamente, com significativo benefício econômico e ambiental por poupar o uso de recursos da natureza. Contudo, os avanços neste setor são incipientes, considerando que, conforme pesquisa, 1.227 municípios brasileiros (cerca de $22 \%$ do total) operam programas de coleta seletiva, ou cerca de 35 milhões de brasileiros (17\%) têm acesso a programas municipais de coleta seletiva no país (CEMPRE, 2018).

Estes estudos corroboram a afirmação do Instituto de Pesquisa Econômica Aplicada (IPEA) de que, caso a reciclagem fosse universalizada, geraria uma renda adicional significativa por ano (IPEA, 2010). Vale destacar ainda a existência de outros benefícios ambientais (Demajorovic \& Lima, 2013), tais como: redução de danos ao ciclo hidrológico, perda de biodiversidade (devido à supressão e uso de áreas de florestas para a extração de matéria-prima virgem) e redução do consumo direto de energia. Quanto aos benefícios à saúde humana, ressalta-se a reduções de emissões atmosféricas geradas através dos aterros e minimização dos riscos de doenças (Ribeiro et al., 2014).

No Brasil, a reciclagem teve início através da catação individual de resíduos sólidos. Os catadores individuais são "os mais pobres entre os pobres" urbanos, os trabalhadores com menor status social, para quem a coleta de lixo nas ruas é geralmente feita de forma precária. Não raras vezes, a catação representa a única fonte de renda para a sobrevivência (Bhowmik, 2002). A exclusão social e violação de direitos foram vetores para a criação da primeira associação de catadores no ano de 1985 em São Paulo a partir do trabalho de irmãs beneditinas com pessoas em situação de rua que viviam da coleta de lixo (Silva, 2006; Veronese, 2016).

A perspectiva de organização, geração de renda e autonomia motivaram, durante toda a década de 1990, a ampliação de organizações de catadores em diversas cidades do Brasil. Tais associações e cooperativas se apresentaram como importante inovação social, pois reduziram vulnerabilidades e riscos do trabalho de catação solitária no ambiente inóspito das ruas e minimizaram a vulnerabilidade nas negociações com as indústrias ou com os intermediários que compram o seu material, produzindo melhorias financeiras (Calderoni, 1998). Muitos outros benefícios são registrados na literatura sobre o associativismo destes trabalhadores que se unem a coletivos que empreendem juntos: tendem a desenvolver uma identidade de resistência, superando em alguma medida o estigma e a desqualificação social; desenvolvem um conhecimento bastante superior sobre o processo de reciclagem; experimentam condição de maior segurança no trabalho; aumentam sua autoestima (Pizzio, 2007); participam da gestão da organização com aprendizagens políticas e pessoais; e fortalecem sua rede de proteção e pertencimento social (Ferrarini \& Veronese, 2010).

$\mathrm{Na}$ trilha destes processos organizativos, a partir da articulação de catadores, organizações da sociedade civil, poder público e setor privado, foi oficialmente criado, em 1999, o Movimento Nacional dos Catadores de Materiais Recicláveis 
(MNCR) com o objetivo de "garantir o protagonismo dos próprios catadores na sua luta" (MNCR, 2014). Para tanto, foi fundamental a valorização da categoria de catador por meio da ressignificação de sua identidade coletiva e dos novos sentidos atribuídos ao seu trabalho, como um valioso serviço de utilidade pública prestado às cidades (Lima, 2008).

Os avanços se seguiram com a aprovação e sanção da Política Nacional dos Resíduos Sólidos (PNRS) em 2010 - Lei no 12.305/2010 (Brasil, $2010)^{1}$, regulamentada no Decreto $n^{\circ} 7.404 / 2010$ (Brasil, 2004), a qual prevê, entre outros instrumentos, a concessão de subsídios e incentivos fiscais para a atividade de reciclagem. Além disso, indica proibições relacionadas ao tratamento inadequado dos resíduos sólidos urbanos e confere responsabilidades aos geradores de resíduos e ao poder público. A PNRS foi mais um importante marco no trabalho cooperativado de reciclagem, pois preconiza a priorização e o apoio previstos às cooperativas e outras organizações de catadores de material reciclável no âmbito da gestão compartilhada dos resíduos sólidos. Mediante este novo cenário, além dos benefícios econômicos e ambientais, o resíduo sólido passou a ser visto por seu valor social como gerador de trabalho e renda e promotor de cidadania.

Todas estas especificidades da atividade de reciclagem apresentam desdobramentos nos indicadores de eficiência, em primeiro lugar, porque os seus efeitos se distribuem horizontalmente em múltiplas dimensões, mas eles parecem também apresentar uma intensidade significativa, ou seja, de incidir verticalmente em cada dimensão. Em segundo lugar, porque os efeitos são observados tanto para fora dos EES - no âmbito da sociedade, com impacto direto nas receitas públicas - quanto para dentro dos empreendimentos. No âmbito da sociedade, foi identificado um estudo que demonstrou a eficiência em termos econômicos (eficiência física, eficiência econômica e eficiência de mercado), mensurando os impactos da reciclagem na estrutura produtiva fluminense, no ano de 2008, a partir da produção de 33 cooperativas de catadores de material reciclável. Naquele ano, cerca de R\$ 34 milhões foram poupados pelo sistema produtivo estadual. Este estudo demonstrou ainda que foi evitado um gasto equivalente a $\mathrm{R} \$ 32,5$ milhões devido à economia com recursos naturais: água, petróleo, bauxita, minério de ferro, carvão mineral e outros insumos (Ribeiro et al., 2014).

\begin{abstract}
Enquanto a racionalidade econômica exige a quantificação da relação custo-benefício dos diferentes modos de tratamento dos resíduos, as externalidades positivas da reciclagem sobre o meio ambiente e a sociedade são frequentemente ignoradas na contabilidade tradicional dos prós e dos contras da gestão de resíduos [...] O impacto econômico da reciclagem poucas vezes é estimado em termos de seus efeitos diretos, sobre as indústrias recicladoras, e também efeitos indiretos, sobre o conjunto das demais atividades econômicas (Ribeiro et al., 2014, p. 192).
\end{abstract}

Apesar de mencionar o aspecto social ligado ao trabalho desempenhado pelos catadores, o referido estudo não mensurou os efeitos sociais indiretos

\footnotetext{
${ }^{1}$ Aprovada em 2010, esta lei instituiu a Política Nacional de Resíduos Sólidos, a qual atribui a estados e municípios o cumprimento das seguintes metas: inclusão dos catadores; proibição e a erradicação dos lixões até 2014, com a criação de aterros que atendam às legislações; instalação de compostagem para atender toda a população; e organização da coleta seletiva e o controle de seus custos de operação, incentivando a participação de catadores em cooperativas a fim de melhorar suas condições de trabalho.
} 
à sociedade e ao governo em termos de substituição de funções de proteção e promoção social que o Estado e o mercado deveriam prover, tampouco os efeitos diretos na vida dos trabalhadores. Ademais, não foram identificadas produções na literatura brasileira acerca da eficiência no interior dos EES de reciclagem, em suas múltiplas dimensões, considerando a social, econômica, política, ambiental e humana. Tal lacuna justificou este esforço inédito de criação e de aplicação de indicadores.

Do ponto de vista social, a análise da eficiência é importante para demonstrar os valores que os EES realmente entregam a seus trabalhadores e à sociedade, valores estes invisibilizados sob o manto da mensuração economicista mercantil. Destaca-se ainda a urgência deste novo olhar sobre a mensuração da eficiência multidimensional dos EES de reciclagem, na medida em que, apesar dos referidos avanços, os catadores ainda hoje vivenciam condições de vida precárias na periferia das grandes cidades.

Pensar uma maneira multidimensional e sistêmica de avaliar a eficiência de EES não é tarefa simples, pois envolve no mínimo um sentido complexo das relações que se estabelecem nesses empreendimentos, da infraestrutura, das condições econômicas, culturais e sociais dos sócios e do contexto local, ambiental e político onde estão inseridos. Tal exercício requer pensar as partes ou dimensões de forma articulada, bem como indicadores para uma apreensão ampla do que se está avaliando.

\section{A construção de indicadores multidimensionais para a eficiência sistêmica}

Significativos esforços para a mensuração de atividades econômicas e processos sociais que não se reduzem à racionalidade mercantil vêm sendo empreendidos nos últimos anos (Kraychete, 2012). É crescente o interesse neste tipo de mensuração por conta da proliferação de economias alternativas, processos e inovação social, desenvolvimento local, empreendedorismo com propósito social e todo um conjunto de iniciativas com impactos multidimensionais. O campo da reciclagem, como setor produtivo de ganhos econômicos, foi reconhecido há pouco tempo. Com o aumento do consumo e do descarte e do valor das matérias-primas utilizadas para a produção de bens de consumo nos grandes centros urbanos, a coleta seletiva se tornou um importante instrumento para os municípios (Veronese, 2016).

No Estado do Rio Grande do Sul, políticas pioneiras tiveram início no final de década de 1990. Tais políticas estimularam o surgimento de cooperativas, com capacidade de estabelecimento de convênios com as prefeituras. Através do trabalho associado, catadores individuais, submetidos a um conjunto de vulnerabilidades, passaram a obter melhoria de seus ganhos (Calderoni, 1998), a desenvolver uma identidade de resistência e a superar o estigma e a desqualificação social que os marcam amiúde, em função da atividade de catação (Pizzio, 2007; Ferrarini \& Veronese, 2010).

Entretanto, como de fato analisar estes ganhos para os sujeitos e contextos envolvidos? E como avaliar se tais EES são eficientes, visto que os instru- 
mentos e indicadores convencionais não se aplicam à realidade desses empreendimentos?

$\mathrm{O}$ esforço inicial desta pesquisa consistiu na identificação dos elementos e condições que concorrem para a viabilidade e a reprodução dos EES, as quais estão relacionadas a formas concretas de produção que combinam relações técnicas e relações sociais. Um determinado bem ou serviço é um processo de reprodução de determinadas relações sociais, visto que a força de trabalho não se constitui em mercadoria. Portanto, três elementos são relevantes para a análise da eficiência de EES: a) o que pretendem viabilizar ou (re)produzir; b) a interferência dos diferentes espaços e; c) as especificidades dos setores populares (Kraychete, 2012).

O passo seguinte foi a construção de indicadores apropriados à economia solidária, mas também atendendo a especificidades do segmento de reciclagem. Um indicador é um "conjunto de dados que possibilita simplificar, medir, comparar e comunicar informação, possibilitando visualizar o comportamento dos agentes ou dos sistemas" (Wautiez, et al., 2003). Tais indicadores deveriam abranger as mais diversas questões relacionadas ao grupo de cooperados, das necessidades individuais às coletivas, num processo de construção dialogada que considere tanto os aspectos internos ao EES, quanto os externos, relativos aos benefícios sociais à comunidade do entorno e à preservação ambiental.

A elaboração dos indicadores deu-se, num primeiro momento, pela busca de indicadores já utilizados no campo da economia solidária e do desenvolvimento local e que pudessem ser adaptados ou remodelados para a construção de um instrumento de mensuração quantitativa da eficiência dos EES de reciclagem. Posteriormente, foi realizada uma pesquisa de natureza exploratória através de observação em reuniões do Fórum de Recicladores do Vale dos Sinos e em três cooperativas de recicladores vinculadas a este Fórum, a qual possibilitou a adequação de indicadores à realidade e às especificidades da atividade de reciclagem (Deslauriers \& Kérisit, 2012).

Tais indicadores foram extraídos das seguintes pesquisas:

- Programa Integrado de Recuperação de Áreas Degradadas (PIRAD) $)^{2}$, cujas ações principais focaram na educação ambiental e na economia solidária. Os indicadores deste programa foram desenvolvidos, primeiramente, a partir da reflexão a respeito da terminologia "riqueza" inspirada por (Sen, 2000) e da sustentabilidade multidimensional (Sachs, 2002; Veiga, 2006; Stoffel \& Colognese, 2015), a fim de captar a complexidade dos efeitos da política pública. Desta reflexão foram elencadas quatro dimensões para análise: econômica, social, política e humana. Em segundo lugar, foram construídos indicadores de dois tipos para cada dimensão: operacionais, (referentes às atividades previstas) e os de efetividade, (referente aos objetivos do projeto) (Armani, 2001), cuja finalidade era captar de forma mais complexa o êxito e os limites do programa. Em terceiro lugar, a fim de enfatizar os aspectos de agenciamento dos sujeitos, foi agregada a análise de competências através da tríade conhecimento-habilidade-atitude (CHA) (Rios, 2003). As três dimensões da competência (teórica, técnica e ética) na formação profissional

\footnotetext{
${ }^{2}$ Desenvolvido no período de 1999 a 2002 pela Fundação Estadual de Planejamento Metropolitano e Regional (Metroplan), em parceria com a Sociedade de Cooperação Alemã (GTZ) - atualmente GIZ - e a Refinaria Alberto Pasqualini - Petrobrás (Refap), em três grandes regiões ligadas a sub-bacias de arroios em áreas ambientalmente degradadas e onze municípios no Estado do RS. O PIRAD articulou a intervenção ambiental com ações de geração de renda e inclusão social através de metodologias participativas numa perspectiva de desenvolvimento local integrado e sustentável.
} 
foram aplicadas à formação do cidadão na aquisição de capacidades e no exercício de direitos (Ferrarini, 2008). Este estudo contribuiu fundamentalmente para a escolha das dimensões relevantes e suas definições (colunas 1 e 2 da Tabela 1), considerando a realidade à qual o instrumento se aplica.

- Microempreendedorismo e Associativismo em Países de Desenvolvimento Periférico ${ }^{3}$ : na referida pesquisa, os EES foram submetidos à observação presencial do seu funcionamento e à coleta de informações e documentos, de acordo com dois vetores. $\mathrm{O}$ primeiro foi o vetor solidário, o qual permitiu a observação da autogestão e da cooperação, desdobradas em indicadores observáveis ligados a: sistema de decisão, eleições e registros oficiais; aporte em capital e trabalho; democracia, gênero, liderança, processo de trabalho, critérios de remuneração, convivência e participação na comunidade e em movimentos sociais. O segundo foi o vetor empreendedor, o qual observou a eficiência e sustentabilidade através de indicadores relacionados a: remuneração, liquidez, custos, investimentos, planejamento, sustentabilidade, parcerias, qualificação do trabalho e melhorias tecnológicas.

- Mapeamento nacional de economia solidária: identificou e produziu dados sobre 19.708 EES, cuja análise teve os seguintes focos: processos de gênese e desenvolvimento, características gerais, tipologias com base em critérios sociais e econômicos dos EES. O Mapeamento gerou o Sistema de Informação da Economia Solidária (SIES) (Gaiger \& Grupo Ecosol, 2014), o qual também aportou dados específicos e relevantes sobre associações e cooperativas do segmento da reciclagem rurais e urbanas do Brasil.
Estas referências, trazidas para o campo empírico da reciclagem, possibilitaram a criação de um instrumento que foi denominado Índice de Eficiência Multidimensional de Cooperativas de Reciclagem (IEMCR), no qual foram sistematizados e avaliados 22 indicadores observacionais a partir de cinco dimensões (Tabela 1). Será possível observar que já consta um resultado na coluna final. Tal resultado é produto da aplicação do instrumento e será discutido na quarta parte deste artigo.

A cada indicador foi atribuído um peso específico (Tabela 2).

A fim de facilitar a visualização, foi criada uma forma de apresentação do resultado final do IEMCR utilizando o modelo de gráfico tipo radar (Figura 1).

O gráfico tipo radar permite identificar a média alcançada, ou seja, quanto maior a média da dimensão avaliada, melhores serão os resultados de avaliação dos indicadores observacionais pela cooperativa, e quanto menor a média, mais baixa é a adesão aos indicadores. A baixa adesão indica pontos de atenção às cooperativas para possíveis melhorias e discussões junto aos sócios.

A partir da construção dos instrumentos, em 2015 foi realizada a pesquisa qualitativa para a produção de dados primários nos EES pesquisados através de observação participante, três entrevistas semiestruturadas (com representantes ou lideranças a respeito da autogestão dos EES) e três grupos focais (com a participação mínima de seis cooperados). As técnicas foram mediadas pela aplicação dos indicadores.

\footnotetext{
${ }^{3}$ Pesquisa desenvolvida entre três países de desenvolvimento periférico (Portugal, Moçambique e Brasil) no período de 2008 e 2010 pelo Grupo de Pesquisa em Economia Solidária e Cooperativa (EcoSol) da UNISINOS. O objetivo era compreender o empreendedorismo associativo de trabalhadores desempregados ou em condições de desvantagem social no mercado capitalista globalizado. Edital CNPq $02 / 2009$.
} 
TABELA 1 - Indicadores multidimensionais de cooperativas de reciclagem.

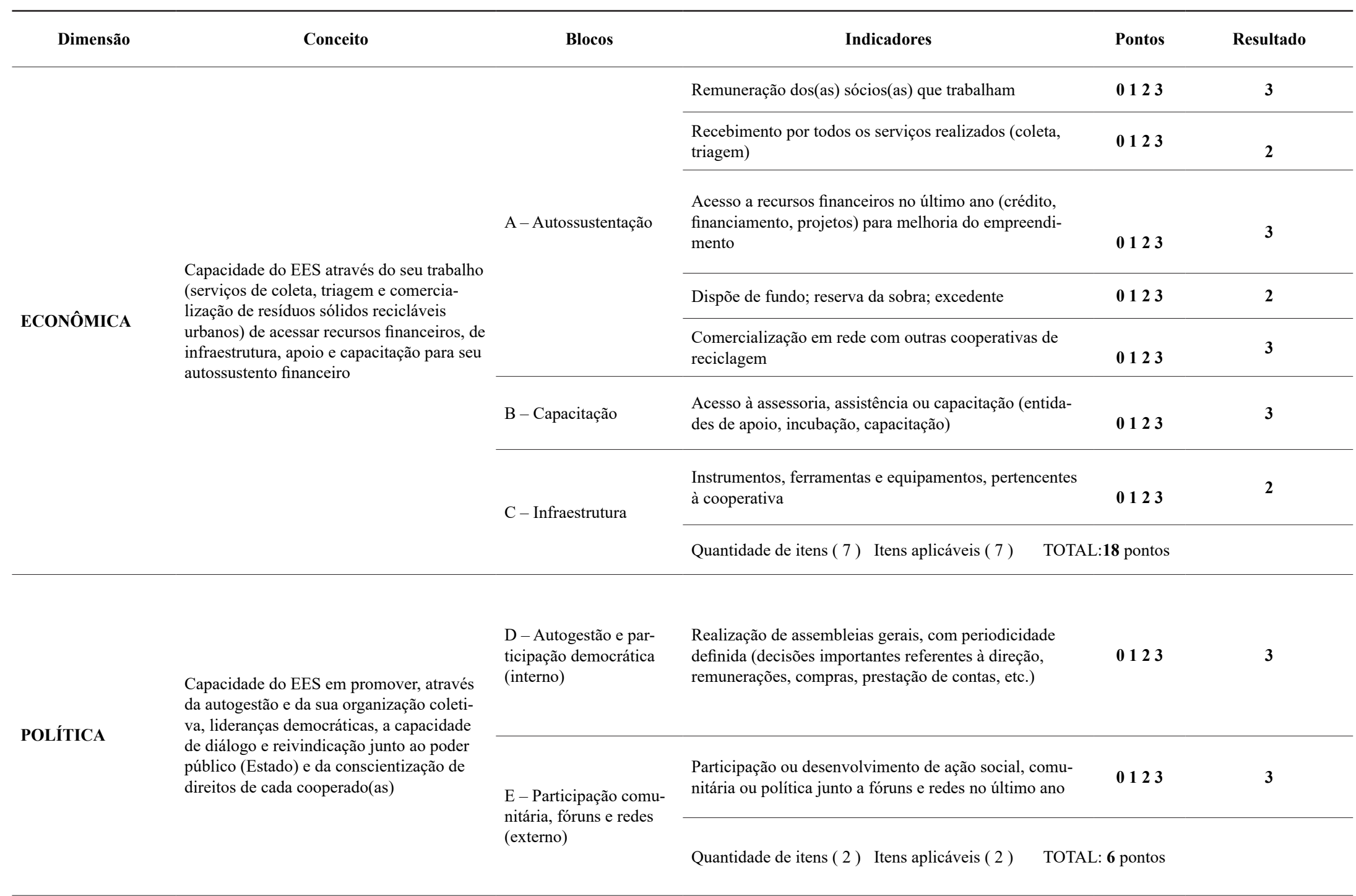


F - Vínculos coopera-

tivos

Capacidade do EES em promover o trabalho em cooperação, crescimento mútuo e de gerar benefícios internos e externos ao empreendimento, relacionados a garantias sociais, de gênero dos(as) cooperados(as)

G - Gênero

Trabalho cooperativo melhora os vínculos entre os sócios(as)

Participação e envolvimento entre homens e mulheres nas atividades e decisões da cooperativa

0123 3

0123

3

Fornecimento de pelo menos um benefício, ou garantia de direitos aos cooperados(as) que trabalham no em-

$\mathrm{H}$ - Benefícios Sociais preendimento (descanso remunerado, licença-maternida-

0123

3 de, previdência social)

Quantidade de itens ( 3) Itens aplicáveis (3) TOTAL: 9 Pontos

Reconhecimento dos cooperados como agente ambien-

I - Ser agente Am-

tal, na contribuição da conservação do meio ambiente

0123

3

biental através do seu trabalho.

Capacidade do EES em se reconhecer como um agente ambiental, de garantir os controles ambientais e uso adequado de recursos referente à sua operação

Destinação das sobras de resíduos para tratamento adequado (aterro ou outro tipo de tratamento)

0123

3

Licenciamento ambiental em vigor e conhecimento sobre as condicionantes de operação

0123

3 tais

Sensibilização sobre uso adequado de recursos ambien-

tais (água, energia) juntos aos sócios

0123

2

Quantidade de itens (4) Itens aplicáveis (4)

TOTAL: 11 pontos

Formação no ensino fundamental ou ensino médio com-

pleto pelos cooperados(as)

0123

3

K - Educação Formal e

Incentivo ao retorno à escolarização (ensino fundamental e médio)

0123

2

Acesso a locais internos para refeições, descanso ou lazer dos cooperados(as)

0123

2

da autogestão e cooperação, o resgate à

HUMANA educação formal, da identidade cultural, dos vínculos e da melhoria da qualidade de vida dos(as) cooperados(as)

Incentivo à promoção da saúde através de parcerias locais para a realização de tratamentos, exames, vacinas

Uso de equipamentos de proteção individual

Promovem a memória histórica do grupo (registros de fotos, ações e eventos)

0123

0123

2

0123 3

M- Identidade

Quantidade de itens (6) Itens aplicáveis (6)

TOTAL: 13 pontos 
TABELA 2 - Critérios de avaliação dos indicadores multidimensionais de cooperativa de reciclagem.

Peso

3

2

1

0

\section{Critério de avaliação}

Cooperativa atende ao indicador.

Cooperativa atende parcialmente ao indicador (ações em planejamento, sendo discutidas com os cooperados e com as partes interessadas).

Cooperativa não atende ao indicador (não existe planejamento, o tema é de conhecimento, mas não foi discutido em reuniões e assembleias).

A cooperativa desconhece o tema do indicador.

FONTE: elaborado por Maciel (2016).

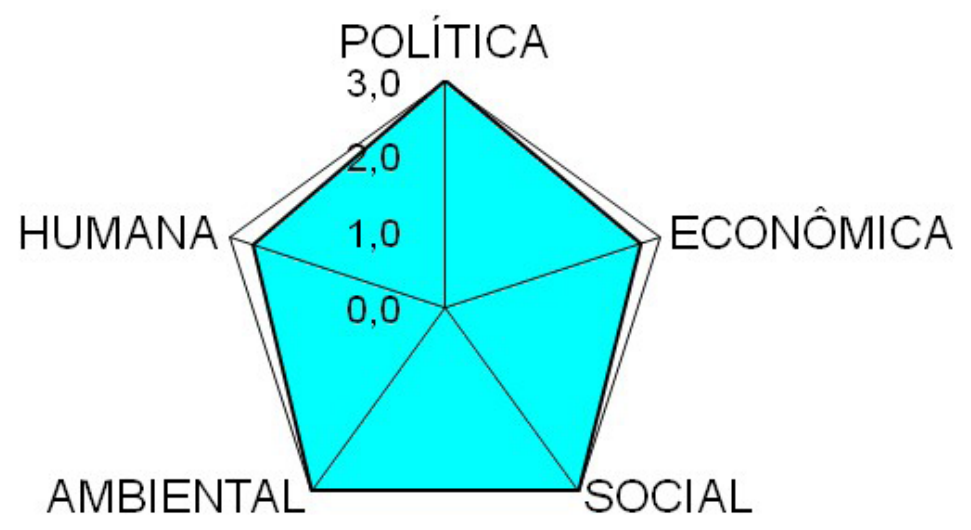

FIGURA 1 - Modelo de Índice de Eficiência Multidimensional de Cooperativas de Reciclagem (IEMCR).

FONTE: elaborado por Maciel (2016). 


\section{A eficiência multidimensional dos empreendimentos de reciclagem}

A cooperativa de reciclagem analisada faz parte do Fórum de Recicladores do Vale dos Sinos, importante instância de mobilização contra os lixões e incineração de resíduos, muito antes da aprovação da Lei Federal 12.305/2010 (Brasil, 2010). Esta lei passou por um longo processo de validação, o que retardou avanços no gerenciamento de resíduos sólidos no Brasil, processo que até pouco beneficiava significativamente o setor privado e excluía, dessa cadeia, os catadores individuais, associações e cooperativas de reciclagem.

A escolha da Cooperativa UNIVALE para a pesquisa seguiu os seguintes critérios: relevante atuação política na causa socioambiental; capacidade de gerar renda a um grande número de pessoas (82 famílias); inserção no SIES; e proximidade da pesquisadora. $\mathrm{O}$ caso será apresentado a partir de dados produzidos de forma qualitativa a fim de oportunizar uma visão mais aprofundada e conferir sentido à análise dos indicadores. Destaca-se que foram adotados nomes fictícios para a identificação dos participantes, seguindo as prerrogativas éticas de anonimato dos entrevistados e considerando o processo de divulgação interna (na cooperativa) e de disseminação externa dos resultados deste estudo.

A UNIVALE representa o modelo de cooperativa de reciclagem mais comum, constituída por ex-catadores individuais de resíduos e por pessoas em situação de desemprego formal. No final de 2009, o grupo de doze de catadores individuais e apoiadores se tornou uma associação. No início, o trabalho era muito sofrido, pois os catadores enfrentavam sol e chuva para coletar o material e auferiam baixa remuneração em função da venda do material para atravessadores. A partir da implementação da coleta seletiva no município, a associação solicitou apoio à prefeitura para viabilizar o aluguel de um galpão e a compra do maquinário. Em 2013 a UNIVALE foi formalizada como cooperativa, passando a realizar a coleta, triagem e comercialização de materiais recicláveis no bairro da Feitoria, município de São Leopoldo.

TABELA 3 - Caracterização da Cooperativa UNIVALE.

\begin{tabular}{ll}
\hline & Questões gerais da cooperativa \\
\hline Situação atual do empreendimento & Operando \\
\hline Possui acesso a computador & Sim \\
\hline Possui acesso à internet & Sim \\
\hline Número de sócios (as) 2015 & $(11) 7$ homens; 4 mulheres \\
\hline Número de sócios (as) 2019 & $(11) 12$ homens; 7mulheres \\
\hline Escolaridade predominante dos sócios(as) & Ensino médio incompleto \\
\hline Tipos de resíduo coletado, triado e comercializado & Papel, papelão, plásticos, alumínio, metais, longa vida, vidros, eletrônicos. \\
\hline
\end{tabular}

FONTE: elaborado por Maciel (2016). 
A Cooperativa tem um histórico consagrado no município; ela é reconhecida por seu trabalho e conta com diversas entidades de apoio (tais como: Unisinos, Cáritas, Fórum Municipal dos Catadores de São Leopoldo e Fórum de Recicladores e Catadores do Vale dos Sinos), assim como apoiadores individuais. Ao longo desses anos, vem disseminando os princípios da economia solidária, tais como a autogestão e o apoio à comunidade. Os recicladores da UNIVALE são responsáveis pela triagem de, em média, 40 toneladas desse material por mês.

Conforme a análise quantitativa geral do IEMCR (Tabela 4), a UNIVALE apresentou boa adesão aos indicadores observacionais propostos na avaliação, atendendo 57 pontos de 66 pontos possíveis na avaliação, com $86 \%$. De acordo com os critérios de avaliação (pesos) - ver quadro 2 - a cooperativa apresentou: $63,64 \%$ de atendimento ao peso 3 (a cooperativa atende ao indicador); $31,82 \%$ de atendimento ao peso 2 (a cooperativa atende parcialmente ao indicador, ou seja, há ações em planejamento, sendo discutidas com os cooperados e com as partes interessadas); e 4,54\% de atendimento ao peso 1 (a cooperativa não atende ao indicador, o que significa que não existe planejamento; o tema é de conhecimento, mas não foi discutido em reuniões e assembleias). Quanto ao peso 0 (a cooperativa desconhece o tema do indicador), não houve registro.

A Figura 2 permite visualizar as dimensões de maior e menor eficiência, na medida em que quanto mais preenchido for o gráfico (de dentro para fora), entre a média 0 a 3 , maior a eficiência alcançada para cada dimensão avaliada.

Na Tabela 5 é possível identificar o total de indicadores avaliados por dimensão, a respectiva pontuação total obtida (soma total dos pesos atribuídos), e a média alçada (total da pontuação obtida/pelo número de indicadores) e o percentual (pontuação obtida por dimensão/total de pontuação obtida em todas as dimensões).

TABELA 4 - Resultados do Índice de Eficiência Multidimensional das Cooperativas de Reciclagem.

UNIVALE

\begin{tabular}{|c|c|}
\hline $\begin{array}{l}\text { Pontuação realizada ( } 66 \text { pontos possíveis) } \\
22 \text { indicadores avaliados }\end{array}$ & 57 \\
\hline Índice de Eficiência Multidimensional de Cooperativa de Reciclagem & $86 \%$ \\
\hline $\begin{array}{l}\text { Índice de atendimento dos indicadores } \\
\text { Peso } 2 \text { (a cooperativa atende parcialmente ao indicador, ações em planejamento, sendo discutidas com os coopera- } \\
\text { dos e com as partes interessadas) }\end{array}$ & $31,82 \%$ \\
\hline $\begin{array}{l}\text { Índice de atendimento dos indicadores } \\
\text { Peso } 1 \text { (a cooperativa não atende ao indicador (não existe planejamento, o tema é de conhecimento, mas não foi } \\
\text { discutido em reuniões e assembleias) }\end{array}$ & $4,54 \%$ \\
\hline $\begin{array}{l}\text { Índice de atendimento dos indicadores } \\
\text { Peso } 0 \text { (a cooperativa desconhece o tema do indicador) }\end{array}$ & $0 \%$ \\
\hline
\end{tabular}

FONTE: elaborado por Maciel (2016). 


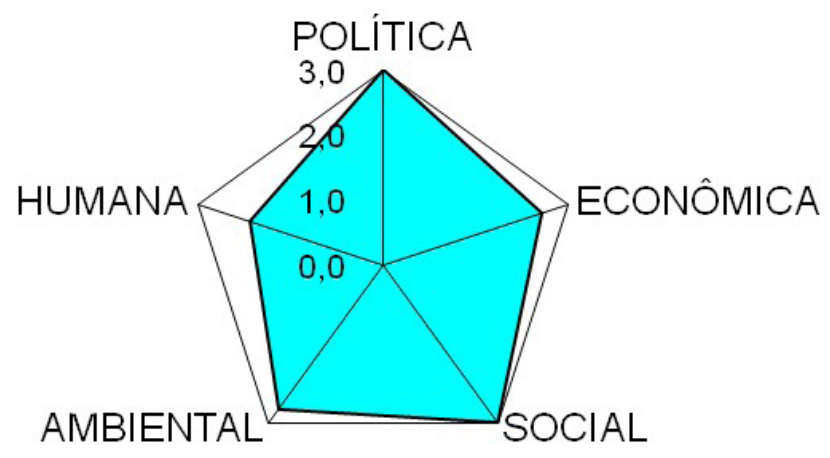

FIGURA 2 - Índice de Eficiência Multidimensional da Cooperativa UNIVALE.

FONTE: elaborado por Maciel (2016).

TABELA 5 - Resultados detalhados do Índice de Eficiência Multidimensional das Cooperativas de Reciclagem UNIVALE.

\begin{tabular}{llllll}
\hline $\begin{array}{l}\text { DIMENSÕES AVA- } \\
\text { LIADAS }\end{array}$ & TOTAL DE INDICADORES & \multicolumn{2}{c}{$\begin{array}{c}\text { TOTAL PONTUAÇÃO OB- } \\
\text { TIDA }\end{array}$} & MÉDIA & $\%$ \\
\hline POLÍTICA & 2 & 6 & 3,00 & $11 \%$ \\
ECONÔMICA & 7 & 18 & 2,57 & $32 \%$ \\
SOCIAL & 3 & 9 & 3,00 & $16 \%$ \\
AMBIENTAL & 4 & 11 & 2,75 & $19 \%$ \\
HUMANA & 6 & 13 & 2,17 & $23 \%$ \\
& $\mathbf{2 2}$ & $\mathbf{5 7}$ & - & $\mathbf{1 0 0 \%}$ \\
\hline
\end{tabular}

Analisando a eficiência do EES em cada dimensão à luz da média geral de eficiência multidimensional - que foi de $86 \%$ - é possível perceber que as dimensões econômica e social encontram-se equilibradas e compatíveis com a média geral, ou seja, a remuneração é razoável (apesar de ainda não ser o esperado pelos sócios), e as condições do trabalho cooperativo e as garantias sociais também encontram-se razoavelmente atendidas.

Sobre a dimensão econômica, a pesquisa revelou que todos os cooperados vivem $100 \%$ do trabalho da cooperativa, e eles consideram que houve melhorias para as suas famílias. O que a cooperativa proporciona atualmente supre as necessidades básicas, mas, "[...] há um acordo de trabalhar para viver e não para sobreviver. [...] A meta é melhorar. Isto tem acontecido a partir do contrato da prefeitura" (João).

A comercialização coletiva vem sendo realizada através do Fórum de Recicladores do Vale dos Sinos, com ganhos na qualificação do material. A Cooperativa recebe apoio da Unisinos e da 
prefeitura para capacitações e acesso a verbas via projetos. A infraestrutura é o maior impedimento para melhorias, pois o galpão ocupado atualmente é alugado.

Quanto à dimensão social, os entrevistados referiram que o trabalho cooperativo melhora os vínculos entre os sócios, e há uma boa sinergia no grupo: "[...] eu vim pra cá por causa de dinheiro, mas eu vi que não era bem assim, pois não levava em consideração outras questões, da compreensão que um tem com outro, do acolhimento. Eu mesmo considero a cooperativa minha segunda casa, uma segunda família. Um espaço agradável e saudável onde todos dão risadas" (José). Esta fala reveste de qualidade o dado identificado no IEMRC acerca do equilíbrio entre as dimensões social e econômica, expressando também a racionalidade econômica substantiva vivenciada na prática. A tradicional concepção de eficiência como sinônimo de lucratividade jamais captaria um agir econômico imbricado no social (Polanyi, 1977). A flexibilidade com relação à carga horária de trabalho, o cuidado com o outro e a inclusão sem preconceitos também foram elementos destacados: "[...] não há distinção por ser homem ou mulher, os assuntos são discutidos e são votados de maneira igual entre os cooperados" (Francisco).

A dimensão política apresentou média 3,00 com o total de pontos adquiridos (6) dividido pelo total de indicadores avaliados (2), o que denota um excelente exercício de democracia interna e de participação externa, que é algo bastante desafiador, mas também muito característico do tipo ideal de EES e estimulado pelos formadores e apoiadores no campo da economia solidária. A eficiência na dimensão política sugere boas condições de perenidade de empreendimento.
Qualitativamente, o grupo relatou que as assembleias são anuais, porém as pautas prioritárias têm sido decididas em reuniões curtas. Os trabalhadores entendem que esta maneira é boa, pois "[...] foram reduzidas as reuniões longas e a comunicação melhorou, contribuindo para a produção" (Maria). Quanto à participação externa, muitos trabalhos estão sendo realizados nas escolas municipais do entorno da cooperativa e ações de panfletagem no bairro, mas "[...] as pessoas do próprio bairro nem sempre estão interessadas, $e$ muitos dos materiais que chegam de doação na cooperativa são de moradores de outros bairros" (Joana). Há também boa articulação em fóruns e redes. De fato, politicamente a pesquisa qualitativa revelou aspectos altamente positivos. Em parte, isso se deve ao ambiente de forte atuação política ligado ao Fórum de Recicladores do Vale dos Sinos em que a Cooperativa se gestou, mas também por ter um curto tempo de vida, e processos instituídos de poder ainda não terem se cristalizado, como é o caso da baixa rotatividade de lideranças em muitos EES.

A dimensão ambiental apresentou média 2,75, composta pelo total de pontos adquiridos (11) dividido pelo total de indicadores avaliados (4), a qual também se mostrou bastante eficiente, demonstrando que houve uma apropriação simbólica do papel de agente ambiental e uma materialização dos procedimentos técnicos e legais de cuidado ao meio ambiente. As entrevistas individuais e grupais mostraram que os trabalhadores de fato reconhecem o seu papel como agentes ambientais e a importância da cooperativa para a preservação do meio ambiente: "[...] se não fosse a cooperativa fazer este trabalho, quem faria? Para onde esse material iria? E quantas árvores poderiam ser derrubadas?" (Maria). A Cooperativa também atende a todos os 
requisitos de separação e destinação adequada dos rejeitos e de colaboração mútua entre cooperativas. O óleo de cozinha é encaminhado para a Cooperativa Mundo Mais Limpo ${ }^{4}$, que realiza o beneficiamento, transformando-o em sabão em barra e detergente. Há também trabalho de sensibilização ambiental voltado à comunidade.

A dimensão humana apresentou média 2,17, resultante do total de pontos adquiridos (13) dividido pelo total de indicadores avaliados (6), ficando um pouco abaixo da média geral das outras dimensões. Houve questionamentos em espaços de debate acadêmico acerca da pertinência da definição desta dimensão, haja vista que todas as dimensões são protagonizadas pelos seres humanos. Entretanto, a escolha por distingui-la objetivou iluminar aspectos pessoais, considerando, em primeiro lugar, que cada indivíduo é único e, em segundo lugar, que os processos coletivos passam pela subjetividade de cada participante.

Com relação ao primeiro aspecto, a singularidade de cada indivíduo e sua relevância na análise do EES se vincula à referida epistemologia sistêmica, agora não diretamente naquele sentido de interdependência entre sociedade, ambiente e economia que fundamenta a racionalidade econômica substantiva, mas de interdependência entre a reciprocidade e outras formas de integração econômica presentes nos EES, as quais foram negadas nas métricas mercantis. Quando Polanyi argumenta que os economistas neoclássicos teriam tomado a parte pelo todo, supondo a economia como sistema autorregulado e desimbricado (desimbedded), ele se refere à consideração da forma de integração econômica da troca como definidora. A troca se apresenta nos movimentos frequentes de compra e venda e pressupõe um equilíbrio entre oferta e demanda, bem como um sistema de preço (atos de barganha). Na economia capitalista, a troca se expressa através do mercado. Para tais economistas, todas as economias, inclusive pré-modernas, teriam sido mercantis em sua essência (Polanyi, 1977).

Em contraposição, Polanyi (1977) afirma que sistemas históricos se especificam pelo modo como instituem outras três formas de intercâmbio na produção substantiva da vida, para além das trocas. São elas: reciprocidade, redistribuição e domesticidade. A reciprocidade - essencial para este estudo - é um complexo sistema de dádivas entre os membros da comunidade que se efetivam através de relações simétricas e interdependentes. Já a redistribuição é a contrapartida de uma entidade hierarquicamente instituída e socialmente legitimada, com base na centralidade (papel desempenhado pelo Estado na sociedade moderna), a qual visa compensar diferenças e gerir necessidades da coletividade (Granovetter, 1985; Coraggio, 2009; Silva et al., 2011). A domesticidade, por sua vez, consiste na produção para uso próprio ou para prover as necessidades domésticas, não se vinculando a motivações de ganho nem a mercados. O seu padrão é o do grupo fechado, próximo à autarquia (Polanyi, 1980), dadas as especificidades das relações de hierarquia intergeracional. Este princípio sempre desempenhou um importante papel na história da humanidade (Silva et al., 2011). Nos EES de reciclagem, a domesticidade não raras vezes se funde à reciprocidade na medida em que se estabelecem laços de entreajuda

${ }^{4}$ É uma das sete cooperativas de reciclagem de São Leopoldo, atuante no Fórum de Recicladores do Vale dos Sinos e no Fórum dos Recicladores de São Leopoldo. 
entre as famílias de catadores. Este entrelaçamento entre dinâmicas socioeconômicas é observado, em especial, na vivência das trabalhadoras que, em contexto de pobreza e vulnerabilidade social, precisam articular os cuidados dos filhos e de outros dependentes com as demandas laborais. Portanto, o conjunto de interações econômicas que ocorre simetricamente entre os indivíduos que compõe a totalidade do empreendimento da produção econômica é constituinte da eficiência do EES.

Em segundo lugar, no tocante à subjetividade, o fracasso do projeto emancipatório da modernidade (Santos, 2000; Ferrarini, 2008) significou também o esgotamento do paradigma determinístico da ciência moderna cartesiano-positivista, o qual conferiu precedência às condições objetivas na constituição do indivíduo. Na contemporaneidade, considerando os avanços em teorias pedagógicas, psicológicas e biológicas, bem como o legado dos fracassos das promessas modernas, emerge a necessidade de uma dialética ou integração entre condições objetivas e disposições subjetivas nas dinâmicas sociais. A escolha por captar elementos subjetivos de autocuidado, autorrealização, saúde, educação e lazer, os quais possivelmente ficariam encobertos se analisada apenas a dimensão social, pareceu acertada quando se considera a referida dialética.

A pesquisa qualitativa sobre a dimensão humana expressou não haver regras que determinem que um cooperado deva atender algum requisito de escolaridade para trabalhar na cooperativa, porém há um reconhecimento de que a educação formal é importante para o avanço da cooperativa, principalmente em questões técnicas relacionadas à gestão financeira, jurídica e ambiental. Na UNIVALE não há atividades voltadas especificamente à qualidade de vida. Todos utilizam o Sistema Único de Saúde, mas o uso de equipamentos de proteção individual (EPI) foi um ponto fraco da avaliação. Estes dados confirmam a média desta dimensão avaliada, e não chegam a surpreender, pois em geral há sacrifícios nesta esfera para a viabilização de um empreendimento. A identificação desta fragilidade pode subsidiar os sócios e apoiadores a lançarem mão de alternativas. Muitas vezes, tais alternativas não requerem investimentos financeiros, pois pequenas mudanças na rotina ou na estrutura podem gerar grandes efeitos relativos à saúde e ao bem-estar.

A congruência entre o IEMCR e os dados qualitativos demonstrou que o instrumento criado é confiável. A pesquisa na UNIVALE, a partir do aprofundamento dos dados agregados nos indicadores, permitiu também identificar fragilidades e produzir uma pauta propositiva. As fragilidades podem ser sucintamente descritas para cada uma das seguintes dimensões:

- Econômica: necessidade de composição de um fundo, ausência de cobrança por alguns serviços realizados e ociosidade de alguns equipamentos pertencentes à cooperativa;

- Ambiental: certo desperdício de recursos, como água e energia elétrica, decorrente da ausência de instrumentos de gestão para o monitoramento do consumo.

- Humana: falta de incentivo à escolarização, necessidade de criação de ambientes adequados para refeições e descanso e de incentivo à promoção à saúde e ao uso de EPI.

Dentre as proposições para a superação dos desafios, destacam-se: capacitação técnica do grupo para atender às necessidades de operação da Cooperativa, a exemplo do licenciamento ambiental, de controles operacionais ambientais, de ações voltadas à saúde e segurança no trabalho, da gestão 
contábil e de rotinas administrativas (secretariado); busca por novas receitas desvinculadas do contrato do município; investimentos em uma sede própria; revezamento de lideranças com novos cooperados; aumento da comercialização em rede; melhoria da relação com a comunidade local e promoção de ações relacionadas à qualidade de vida dos cooperados, em particular à saúde e segurança dos trabalhadores.

\section{Considerações finais}

A cultura da avaliação encontra-se cada vez mais presente em instituições sociais e econômicas, dado que valores empreendedores estão sendo incorporados à gestão pública e privada, de forma gradual, mas continuada. Portanto, se nunca foi tão importante mensurar a eficiência, também nunca foi tão necessário repensar conceitos, critérios e métodos frente à diversidade de contextos a serem avaliados.

A realidade dos EES é bastante específica, pois eles precisam conjugar eficiência econômica com finalidade social. Quando avaliados a partir de instrumentos, critérios e indicadores típicos de uma perspectiva economicista mercantil, os resultados financeiros contabilizados, não raras vezes, indicam baixos ganhos financeiros para os trabalhadores. Tais avaliações costumam induzir à definição da economia solidária como forma precária de inclusão laboral. No entanto, em lugar de contrapor-se aos imperativos de eficiência, a cooperação na gestão e no trabalho atua como vetor de racionalização do processo produtivo, com efeitos tangíveis e vantagens reais comparativamente ao trabalho individual e à cooperação induzida entre os assalariados pela empresa capitalista (Peixoto \& Lopes, 1999; Gaiger, 2009).

$\mathrm{O}$ ambiente participativo facilita a comunicação, a identificação de dificuldades e a proposição de inovações, elementos que inclusive vêm ao encontro de requisitos e métodos preconizados pela gestão moderna. Ademais, o interesse dos trabalhadores em garantir o sucesso do empreendimento estimula o empenho, havendo aprimoramento do processo produtivo, eliminação de desperdício e de tempos ociosos, qualidade final do produto ou dos serviços e redução do absenteísmo (Defourny, 1988; Carpi, 1997). Há ainda um conjunto de efeitos externos ao EES que incide sobre o meio ambiente (em prol de sua preservação) e sobre as relações da comunidade em geral, imprimindo à realidade um sentido oposto às desigualdades motivadas pelo capitalismo.

Em outras palavras, os EES acabam entregando muito mais aos trabalhadores e à sociedade, pois, diferentemente da empresa capitalista, eles não exteriorizam custos sociais e ambientais e não adotam medidas flexíveis e inovadoras em processos de reestruturação. Apesar de os EES assumirem o cuidado com o trabalhador, com a comunidade e com o meio ambiente, estes efeitos são invisibilizados. Para que haja justiça ao papel que os EES desempenham, torna-se necessário a busca por instrumentos apropriados à captação e mensuração dos efeitos tangíveis e intangíveis dos EES.

Este trabalho apresentou uma construção inédita de um instrumento de mensuração da eficiência multidimensional dos EES de reciclagem, baseada nos preceitos da economia substantiva como processo de institucionalização da interação entre o ser humano e ambiente natural e social (Polanyi, 1977), numa perspectiva sistêmica capaz de religar o que a modernidade científica e capitalista separou 
(Morin, 2008) e em modelos produzidos a partir de realidades emergentes e com segmentos específicos da economia solidária (Ferrarini, 2008; Gaiger \& Grupo Ecosol, 2014). A partir de sua criação, o IEMCR foi submetido ao desafio de expressar a eficiência multidimensional do EES de forma quantitativa e visualmente acessível.

A aplicação do instrumento na UNIVALE cooperativa típica do campo de reciclagem no Brasil - revelou a alta eficiência deste empreendimento em todas as dimensões, não sendo de admirar que a fragilidade tenha sido identificada na dimensão humana, relativa ao bem-estar e crescimento pessoal dos sócios. Em geral, estes são os últimos aspectos que se consolidam, a "cereja do bolo", especialmente numa realidade de profunda recessão econômica como a brasileira e num empreendimento ainda em fase de consolidação. Ainda assim, o adensamento do conteúdo oportunizado pela complementaridade com a pesquisa qualitativa demonstrou que houve melhoria significativa com relação à vulnerável condição pregressa dos seus sócios como catadores individuais.

Além da devolução dos resultados da pesquisa (neste caso, feita às lideranças dos EES em reunião do Fórum de Catadores do Vale dos Sinos) ser um elemento de diagnóstico para a cooperativa e de contribuir para a superação de pontos frágeis em prol da melhoria de sua eficiência, há outro aspecto que se poderia descrever como a beleza deste processo avaliativo adequado à realidade do EES: trata-se da promoção de autorreconhecimento dos trabalhadores acerca de suas potencialidades em meio a contextos de desqualificação social.

O estudo concluiu que a avaliação da eficiência se reveste de extrema importância para combater o lugar de invisibilidade e desqualificação de EES. À luz da eficiência como sinônimo de lucro, os EES são penalizados exatamente por aquilo que possuem de melhor. O IEMCR mostrou-se um instrumento compatível para revelar os complexos efeitos dos EES de reciclagem e credível para novas aplicações, podendo também inspirar a criação ou adaptação a outras organizações.

\section{Referências}

ABRELPE - Associação Brasileira de Empresas de Limpeza Pública e Resíduos Especiais. Panorama dos Resíduos Sólidos no Brasil, 2018/2019. Disponível em: <https:// abrelpe.org.br/download-panorama-2018-2019/>. Acesso em: abr. 2020.

ANCAT - Associação Nacional dos Catadores. Anuário da Reciclagem, 2017-2018. Disponível em: $<\mathrm{https} / / /$ ancat.org. br/wp-content/uploads/2019/09/Anua\%CC\%81rio-da-Reciclagem.pdf $>$. Acesso em: abr. 2020.

Armani, D. Como elaborar projetos? guia prático para elaboração e gestão de projetos sociais. Porto Alegre: Tomo Editorial, 2001.

Brasil. Lei federal n. 12.305, de 2 de agosto de 2010. Institui a Política Nacional de Resíduos Sólidos. Brasília: DOU de 03/08/2010.

Brasil. Decreto $n .{ }^{\circ} 5.300$, de 7 de dezembro de 2004. Regulamenta a Lei n..$^{\circ} 7.661$, de 16 de maio de 1988, que institui a Política Nacional de Resíduos Sólidos, cria o Comitê Interministerial da Política Nacional de Resíduos Sólidos e o Comitê Orientador para a Implantação dos Sistemas de Logística Reversa, e dá outras providências. Brasília: DOU de 23/12/2010.

Bhowmik, S. As cooperativas e a emancipação dos marginalizados: estudos de caso de duas cidades na Índia. In: Santos, B. S. (Org.). Produzir para viver: os caminhos da produção não capitalista. Rio de Janeiro: Civilização Brasileira, p. 369-400, 2002.

Calderoni, S. Os bilhões perdidos no lixo. São Paulo: Humanitas Publicações, FFLCH- USP, 1998. 
Carpi, J. La economía social en un mundo en transformación. Revista Ciriec-España, 25, 83-115, 1997. Disponível em: http://ciriec-revistaeconomia.es/wp-content/uploads/ rev25_06.pdf

CEMPRE - Compromisso Empresarial para Reciclagem. Ciclosoft, 2018. Disponível em: <http://cempre.org.br/ ciclosoft/id/9>. Acesso em: abr. 2020.

Coraggio, J. (Org.). Que és lo económico? materiales para un debate necesario contra el fatalismo. Buenos Aires: Ciccus, 2009.

Daft, R. L. Administração. Rio de Janeiro: LTC, 1999.

Defourny , J. Coopératives de production et enterprises autogérées: un esynthèse du débat sur les effets économiques de la participation. Mondes en Développement, 16(61), 139-53, 1988. Disponível em: https://orbi.uliege. be/handle/2268/92899

Demajorovic, J.; Lima, M. Cadeia de reciclagem: um olhar para os catadores. São Paulo: Editora Senac São Paulo; São Paulo: Edições Sesc SP, 2013.

Deslauriers, J.-P.; Kérisit, M. O delineamento de pesquisa qualitativa. In: Poupart, J.; Desauliers, J.-P.; Groulx, L.-H.; Laperièrre, A.; Mayer, R.; Pires, A. A pesquisa qualitativa: enfoques epistemológicos e metodológicos. Petrópolis: Vozes, 3. ed., p. 127-153, 2012.

Ferrarini, A. V. Pobreza: possibilidades de construção de políticas emancipatórias. São Leopoldo: Oikos, 2008.

Ferrarini, A. V.; Veronese, M. V. Piracema: uma metáfora para o microempreendedorismo associativo no Brasil. Outra Economía, 4(7), 131-152, 2010. Disponível em: https:// www.revistaotraeconomia.org/index.php/otraeconomia/ article/view/1308/368

FSIN - Food Security Information Network. Global Report on Food Crises, 2018. Disponível em: <https://www.wfp. org/publications/global-report-food-crises-2018>. Acesso em: ago. 2019.

Gaiger, L. I.; Laville, J.-L. Economia Solidária. In: Cattani, A. D. et al. (Orgs.). Dicionário internacional da outra economia. Coimbra: Almedina, p. 162-168, 2009.

Gaiger, L. I. Eficiência. In: Cattani, A. D. et al. (Orgs.).
Dicionário internacional da outra economia. Coimbra: Almedina, p. 169-174, 2009.

Gaiger, L. I.; Grupo Ecosol. A economia solidária no Brasil: uma análise de dados nacionais. São Leopoldo: Oikos, 2014.

Granovetter, M. Economic action and social structure: the problem of embeddedness in The American Journal of Sociology, 91(3), 481-510, 1985.

IPEA - Instituto de Pesquisas Estatísticas Avançadas. Pesquisa sobre pagamento por serviços ambientais urbanos para a gestão de resíduos sólidos. Relatório de Pesquisa, 2010. Disponível em: <http://www.portalodm.com.br/ relatorio-da-pesquisapagamento- por-servicosambientais-urbanos-paragestao-de-residuos-solidos--bp--313.html > . Acesso em: abr. 2020.

Kraychete, G. Economia popular solidária: indicadores para qual sustentabilidade? In: Kraychete, G.; Carvalho, P. (Orgs.). Economia popular solidária: indicadores para a sustentabilidade. Porto Alegre: Tomo, p. 15-26, 2012.

Lima, C. Catadores de material reciclável em movimento: trajetória de uma identidade coletiva. In: Anais do III Simpósio Lutas Sociais na America Latina - trabalhadores (as) em movimento: constituição de um novo proletariado? Londrina, 24 a 26 de set. de 2008. Disponível em: <http:// www.uel.br/grupo-pesquisa/gepal/terceirosimposio/cristiano_franca_lima.pdf>. Acesso em: abr. 2020.

Machado, N. M C. Karl Polanyi e o "grande debate" entre substantivistas e formalistas na antropologia econômica. Revista Economia e Sociedade, 21(1), 165-195, 2012. Disponível em: http://www.scielo.br/pdf/ecos/v21n1/07.pdf

Maciel, J. P. Indicadores para qual sustentabilidade? elementos teórico-metodológicos para a análise da eficiência multidimensional de empreendimentos econômicos solidários de reciclagem do Vale dos Sinos - RS. São Leopoldo, Dissertação (Mestrado em Ciências Sociais) - UNISINOS, 2016.

Miller, R. Microeconomia: teoria, questões e aplicações. São Paulo: McGraw-Hill, 1981.

MNCR - Movimento Nacional dos Catadores(as) de Materiais Recicláveis. O que é o movimento. São Paulo, 2014. Disponível em: <http://www.mncr.org.br/box_1/o-que-e-o- 
movimento>. Acesso em: abr. 2020.

Morin, E. Introdução ao pensamento complexo. Porto Alegre: Epistemologia e Sociedade, 5. ed., 2008.

Peixoto, J.; Lopes, V. A reestruturação produtiva no Brasil e o caso das empresas industriais sob regime de autogestão ou co-gestão. Rio de Janeiro: COPPE -UFRJ, 1999.

Pizzio, A. A economia solidária e a qualificação social dos trabalhadores empobrecidos. São Leopoldo, Dissertação (Mestrado em Ciências Sociais) - UNISINOS, 2007.

Polanyi, K. The livelihood of man. New York: Academic Press, 1977.

Polanyi, K. A grande transformação: as origens da nossa época. Rio de Janeiro: Campus, 1980.

Razeto, L. Las empresas alternativas. Montevideo: Editorial Nordan-Comunidad, 1990.

Ribeiro, L. C. S.; Freitas, L. F. S.; Carvalho, J. T. A.; Filho, J. D. O. Aspectos econômicos e ambientais da reciclagem: um estudo exploratório nas cooperativas de catadores de material reciclável do Estado do Rio de Janeiro. Nova Economia, 24(1), 191-214, 2014. Disponível em: http://www. scielo.br/scielo.php?pid=S010363512014000100191\&script $=$ sci_abstract\&tlng $=\mathrm{pt}$

Rios, T. A. Ética e competência. São Paulo: Cortez, 2003.

Sachs, I. Caminhos para o desenvolvimento sustentável. Rio de Janeiro: Garamond, 2002.

Santos, B. S. A crítica da razão indolente - contra o desperdício da experiência. Para um novo senso comum: a ciência, o direito e a política na transição paradigmática. Volume1. São Paulo: Cortez, 2000.
Silva, F. A. G.; Calazans, D. L.; González, J. M.; Souza, W. J. Os princípios de economia substantiva de Karl Polanyi em relações de economia solidária: o caso do Povoado Cruz (Currais Novos/RN). Revista Eletrônica de Ciência Administrativa (RECADM), 10(2), 93-106, 2011. doi: 10.5329/ RECADM.20111002007

Sen, A. Desenvolvimento como liberdade. São Paulo: Companhia das Letras, 2000.

Silva, R. B. O movimento nacional dos catadores de materiais recicláveis: atores, governação, regulação e questões emergentes no cenário brasileiro. Interthesis, 3(2), 1-40, 2006. Disponível em: https://periodicos.ufsc.br/index.php/ interthesis/article/view/882

Stoffel J. A.; Colognese, S. A. O desenvolvimento sustentável sob a ótica da sustentabilidade multidimensional. FAE, 18(2), 18-37, 2015. Disponível em: https://revistafae.fae. edu/revistafae/article/view/48

Veiga, J. E. Desenvolvimento sustentável: o desafio do século XXI. Rio de Janeiro: Garamond, 2006.

Veronese, M. V. Associativismo entre catadores de material reciclável urbano. Contemporânea, 6(1), 213-236, 2016. Disponível em: http://www.contemporanea.ufscar.br/index. php/contemporanea/article/view/403

Veronese, M. V.; Gaiger, L. I.; Ferrarini, A. V. Sobre a diversidade de formatos e atores sociais no campo da economia solidária. Cadernos CRH, 30(79), 89-104, 2017. Disponível em: http://www.scielo.br/scielo.php?pi$\mathrm{d}=$ S010349792017000100089\&script $=$ sci_abstract\&tln$\mathrm{g}=\mathrm{pt}$

Wautiez, F.; Soares, C. L. B.; Lisboa, A. de M. Indicadores da economia solidária. In: Cattani, A. D. (Org.). A outra economia. Porto Alegre: Veraz, p. 177-83, 2003. 